\title{
Effect of antiretroviral drugs on the pharmacodynamics of gliclazide with respect to glucose-insulin homeostasis in animal models
}

This article was published in the following Dove Press journal:

Journal of Experimental Pharmacology

23 December 2009

Number of times this article has been viewed

\section{S K Mastan'}

K Eswar Kumar ${ }^{2}$

'Research and Development cell, Jawaharlal Nehru Technological University, Hyderabad, Andhra Pradesh, India; ${ }^{2}$ Pharmacology Division, AU College of Pharmaceutical Sciences, Andhra University, Visakhapatnam, Andhra Pradesh, India
Correspondence: SK Mastan

Pharmacology Division, AU College of Pharmaceutical Sciences, Andhra University, Visakhapatnam-530003,

Andhra Pradesh, India

Tel +9l 9604 I80206

Fax +9| 9985176604

Email shkmastan@gmail.com

\begin{abstract}
The objective of this study was to investigate the effect of oral administration of antiretroviral drugs (indinavir, ritonavir, atazanavir, efavirenz and nevirapine) on the pharmacodynamics of gliclazide in rats (normal and diabetic) and rabbits with respect to glucose-insulin homeostasis to evaluate the safety and effectiveness of the combinations. Blood samples were collected at regular time intervals in rats from retro orbital puncture and by marginal ear vein puncture in rabbits. All the blood samples were analyzed for blood glucose by glucose oxidase-peroxidase method and insulin by a radio immuno assay method. The insulin resistance index and $\beta$-cell function were determined by a homeostasis model assessment. Indinavir and ritonavir alone had significant impact on glucose-insulin homeostasis in animal models among the antiretroviral drugs used in our study. In combination, indinavir and efavirenz significantly reduced the activity of gliclazide, while ritonavir and atazanavir significantly increased the activity of gliclazide. However, nevirapine had no significant effect on the activity of gliclazide. From this study we conclude that glucose-insulin homeostasis disorders associated with antiretroviral drugs are not class-specific, but are drug-specific. So care should be taken when indinavir, ritonavir, atazanavir and efavirenz are prescribed for diabetic patients.
\end{abstract}

Keywords: protease inhibitors, efavirenz, nevirapine, gliclazide, homeostasis model assessment, diabetes

\section{Introduction}

The study of mechanisms of drug interactions is valuable when selecting the drug concentrations that provide rational therapy. Drug interaction studies assume greater importance for drugs that have a narrow margin of safety or where the drugs are used for prolonged periods of time. Diabetes mellitus is one such metabolic disorder that requires drug treatment for prolonged periods and the maintenance of normal blood glucose levels are particularly important in this condition, since both hyperglycemia as well as hypoglycemia are unwanted phenomenon. ${ }^{1}$

Diabetes mellitus is a chronic metabolic disorder characterized by elevated blood glucose levels and disturbances in carbohydrate, fat and protein metabolism with both micro- and macrovascular complications that result in a significant morbidity and mortality. ${ }^{2}$ Type 1 diabetes occurs as a result of a decrease in the synthesis of insulin and type 2 diabetes is characterized by hyperglycemia in the context of insulin resistance and relative insulin deficiency. The number of people suffering from diabetes mellitus worldwide is increasing at an alarming rate with a projected 366 million people likely to be diabetic by the year 2030, (as against 191 million estimated in 2000). ${ }^{3}$ submit your manuscript | www.dovepress.com

Dovepress
Journal of Experimental Pharmacology 2010:2 I-II

(C) 2010 Mastan and Kumar, publisher and licensee Dove Medical Press Ltd. This is an Open Access article which permits unrestricted noncommercial use, provided the original work is properly cited. 
Type 2 diabetes may occur as a result of HIV infection and/or its treatment. Highly active antiretroviral therapy (HAART), a combination of nonnucleoside reverse transcriptase inhibitors (NNRTIs), nucleoside reverse transcriptase inhibitors (NRTIs), and protease inhibitors (PIs) are widely used to control HIV-infection and the development of AIDS. Among the many metabolic perturbations that occur as a result of HIV-infection and its treatment, alterations in normal glucose homeostasis remain particularly prevalent and alarming clinical changes in affected patients. ${ }^{4}$ HAART has been associated with a spectrum of metabolic abnormalities that range from insulin resistance to impaired glucose tolerance, diabetes mellitus, dyslipidemia, and alterations in body fat distribution, ${ }^{5}$ especially with PIs. ${ }^{6}$ Of much concern is the recognition of long-term complications of insulin resistance and hyperglycemia especially in the context of the growing worldwide epidemic of type 2 diabetes mellitus. ${ }^{7}$ Since many studies have suggested that PI therapy is linked to the development of metabolic complications, it is important to introduce therapeutic strategies with fewer side effects, for example the use of NNRTIs an approach which appears successful for the control of HIV infection. ${ }^{8}$

The widely used PIs include ritonavir, atazanavir and indinavir, and NNRTIs include efavirenz and nevirapine. Oral hypoglycemic agents are used in the treatment of type 2 diabetes, and gliclazide; a second generation sulphonylurea derivative, is preferred in such therapy because not only for its antidiabetic activity, but also for the lower occurrence of severe hypoglycemia, antioxidant properties and other hemobiological effects. ${ }^{9}$

Regulation of glucose metabolism is a key aspect of metabolic homeostasis and insulin is the predominant hormone influencing this regulatory system. Insulin plays a key role in the maintenance of glucose homeostasis and is the major modulator of glucose storage and utilization. In this study Glucose was measured as a metabolic control of insulin action. The impairment of glucose homeostasis and increase in plasma glucose levels are associated with diabetes. Insulin resistance is a state where normal or elevated insulin level produces a reduced biological response ${ }^{10}$ and refers to impaired sensitivity to insulin mediated glucose disposal. ${ }^{11}$ Therefore it is of the utmost importance to study glucose-insulin homeostasis, in order to better understand the pathological process of insulin resistance to evaluate the safety and effectiveness of drug combinations. The homeostasis model assessment (HOMA) is a more reliable and validated method to measure insulin resistance and $\beta$-cell function from fasting glucose and insulin.

In our previous studies, ${ }^{12-15}$ we investigated the effect of antiretroviral drugs (indinavir, ritonavir, atazanavir, efavirenz and nevirapine) on the pharmacodynamics of gliclazide in rats (normal and diabetic) and rabbits with respect to blood glucose levels. However, there is no evidence on the effect of antiretroviral drugs on the activity of gliclazide with respect to glucose-insulin homeostasis.

Therefore in this study we investigated the effect of antiretroviral drugs on the activity of gliclazide with respect to glucose, insulin, insulin resistance and $\beta$-cell function in rats (normal and diabetic) and rabbits to evaluate the safety and effectiveness of the combination.

\section{Material and methods}

Gliclazide and antiretroviral drugs were gift samples from Micro Labs (Bangalore, India) and Aurobindo Pharma Ltd (Hyderabad, India), respectively. Alloxan monohydrate was purchased from LOBA Chemie (Mumbai, India). Glucose kits (Span Diagnostics Udhna, India) were purchased from a local pharmacy. All other reagents/chemicals used were of analytical grade.

\section{Animals}

The rats were of either sex, albino, 6 to 7 weeks of age and weighed between 250 to $320 \mathrm{~g}$. The rabbits were also of either sex, albino, $\sim 3$ months of age and weighed between 1.35 to $1.75 \mathrm{Kg}$. Both rats and rabbits were procured from the National Institute of Nutrition, Hyderabad, India. They were maintained under standard laboratory conditions at an ambient temperature of $25 \pm 2{ }^{\circ} \mathrm{C}$ and $50 \% \pm 15 \%$ relative humidity with a cycle of 12 hours light and 12 hours dark. The animals were fed with a commercial pellet diet (Rayan's Biotechnologies Pvt Ltd., Hyderabad, India) and water ad libitum. The animals were fasted for 18 hours prior to the experiment and during the experiment both food and water were withdrawn. The animal experiments were performed after the study protocol had approval from the Institutional Animal Ethics Committee and by the Government regulatory body for animal research. (Reg. No. 516/01/A/CPCSEA). The study was conducted in accordance with the guidelines provided by Committee for the Purpose of Control and Supervision of Experiments on Animals (CPCSEA).

\section{Selection of doses and preparation of oral test solution/suspension}

In clinical practice, antiretroviral drugs and gliclazide in therapeutic doses are administered orally. Hence, human oral therapeutic doses of the respective drugs were extrapolated to rat/rabbit based on body surface area ${ }^{16}$ But the dose of gliclazide for rat experiments was selected as $2 \mathrm{mg} / \mathrm{kg}$ body 
weight based on the influence of the dose-effect relationship of gliclazide on blood glucose in normal rats. Indinavir, ritonavir, atazanavir, efavirenz and nevirapine were orally administered in the dose of 72, 18, 36, 54 and $18 \mathrm{mg} / \mathrm{kg}$ body weight to both normal and diabetic rats and 56, 14, 28, 42 and $14 \mathrm{mg} / 1.5 \mathrm{~kg}$ body weight to normal rabbits, respectively. Gliclazide was orally administered to normal rabbits in the dose of $5.6 \mathrm{mg} / 1.5 \mathrm{~kg}$ body weight. Antiretroviral drugs were suspended in carboxy-methylcellulose (CMC) for oral administration. ${ }^{17-20} \mathrm{~A}$ gliclazide solution was prepared by dissolving it in a few drops of $0.1 \mathrm{~N}$ sodium hydroxide which was then made up to the required volume with distilled water. All the drugs were administered to the respective groups by oral gavage.

\section{Experimental design}

The study consists of four phases. Phase I: dose-effect relationship of gliclazide in normal rats. Phase II: interaction study between antiretroviral drugs and gliclazide in normal rats. Phase III: interaction study between antiretroviral drugs and gliclazide in diabetic rats. and Phase IV: interaction study between antiretroviral drugs and gliclazide in normal rabbits. Each phase from II to IV consists of five groups $(\mathrm{N}=6)$, for the interaction study of the five antiretroviral drugs with gliclazide (single dose study followed by multiple dose study).

\section{Dose-effect relationship of gliclazide in rats}

To a group of six normal rats gliclazide was administered orally ( $1 \mathrm{mg} / \mathrm{kg}$ body weight). At the conclusion of this, following a one week wash out period, the same group was given gliclazide at $2 \mathrm{mg} / \mathrm{kg}$ body weight and finally at $4 \mathrm{mg} / \mathrm{kg}$ body weight. A one-week washout period was maintained between all changes in treatments.

\section{Interaction study between antiretroviral drugs and gliclazide in normal rats}

Each group of six rats was administered with gliclazide, orally. The same group was administered with interacting drug (Indinavir or ritonavir or atazanavir or efavirenz or nevirapine) and the combination of respective interacting drugs and gliclazide. One week washout period was maintained between treatments. After this single dose interaction study the same group was continued with the daily treatment of respective interacting drug for the next eight days with regular feeding. Later after $18 \mathrm{~h}$ fasting they were again given the combined treatment on the ninth day.

\section{Interaction study between antiretroviral drugs and gliclazide in diabetic rats}

Diabetes was induced in rats by the administration of two intraperitoneal doses of alloxan monohydrate, the first being
$100 \mathrm{mg} / \mathrm{kg}$ body weight followed 24 hours later by a second dose of $50 \mathrm{mg} / \mathrm{kg}$ body weight. ${ }^{21}$ After 72 hours samples were collected from all surviving rats by orbital puncture before the serum glucose concentration was determined. Rats with blood glucose levels of $200 \mathrm{mg} / \mathrm{dL}$ and above were considered as diabetic and selected for the study. The same protocol (single dose interaction study followed by multiple dose interaction study) as described in the study in normal rats was performed with a group of six alloxan-induced diabetic rats.

\section{Interaction study between antiretroviral drugs and gliclazide in normal rabbits}

Each group of six rabbits was administered with gliclazide, orally. The same group was administered with interacting drug (Indinavir or ritonavir or atazanavir or efavirenz or nevirapine) and the combination of respective interacting drug and gliclazide. One week washout period was maintained between treatments. After this single dose interaction study the same group was continued with the daily treatment of respective interacting drug for the next eight days with regular feeding. Later after $18 \mathrm{~h}$ fasting they were again given the combined treatment on the ninth day.

\section{Blood sampling, determination of blood glucose and insulin}

Blood samples were withdrawn from the retro orbital plexus ${ }^{22}$ of each rat at 2 hours and then 8 hours and for each rabbit from the marginal ear vein of at 3 hours. These blood samples were analyzed for blood glucose by the glucose oxidase-peroxidase (GOD/POD) method ${ }^{23}$ using commercial glucose kits and plasma insulin was measured by Radio Immuno Assay method.

\section{Determination of insulin resistance index and $\beta$-cell function}

The insulin resistance index and $\beta$-cell function were assessed by the HOMA protocol and were calculated as follows: ${ }^{24,25}$ Insulin resistance $=(\mathrm{FPI} \times \mathrm{FPG}) / 22.5$ and $\beta$-cell function $=$ $(20 \times \mathrm{FPI}) /(\mathrm{FPG}-3.5)$.

Where FPI is fasting plasma insulin concentration $(\mu \mathrm{u} / \mathrm{mL})$ and FPG is fasting plasma glucose $(\mathrm{mmol} / \mathrm{L})$.

\section{Data and statistical analysis}

Data were expressed as mean \pm standard error of mean (SEM). The significance was determined by applying paired Student's $t$-test. 


\section{Results}

\section{Dose-effect relationship of gliclazide in rats}

A dose dependent response was observed with the three oral doses undertaken with gliclazide. The $2 \mathrm{mg} / \mathrm{kg}$ body weight of gliclazide was selected based on an ideal blood glucose reduction which is about $35 \%$. The gliclazide produced hypoglycemic activity with maximum biphasic reduction of $26.77 \% \pm 1.13 \%$ and $28.91 \% \pm 2.53 \%, 38.59 \% \pm 1.58 \%$ and $40.50 \% \pm 1.40 \%$ and $46.28 \% \pm 1.67 \%$ and $50.65 \% \pm 1.46 \%$ at 2 hours and 8 hours with $1 \mathrm{mg} / \mathrm{kg}$ body weight, $2 \mathrm{mg} / \mathrm{kg}$ body weight and $4 \mathrm{mg} / \mathrm{kg}$ body weight of gliclazide, respectively (Figure 1).

\section{Effect of indinavir on the activity of gliclazide}

The levels of blood glucose, insulin, insulin resistance and $\beta$-cell function following gliclazide, indinavir and their combination (single dose and multiple doses) were represented in Table 1 and Table 6. Indinavir alone produced a significant increase in glucose, insulin, insulin resistance index and decrease in $\beta$-cell function. When given in combination indinavir significantly $(P<0.05)$ altered the pharmacodynamics of gliclazide in both rats (normal and diabetic) and rabbits following both single and multiple dose treatments which is reflected by increases in glucose, insulin and insulin resistance together with a decrease in $\beta$-cell function for the diabetic rats. The reduction in gliclazide effect is more marked with the single dose treatment of indinavir rather than with the multiple dose treatment.

\section{Effect of ritonavir on the activity of gliclazide}

The levels of blood glucose, insulin, insulin resistance and $\beta$-cell function following gliclazide, ritonavir and their combination (single dose and multiple doses) are represented in Table 2 and Table 6. Ritonavir alone produced a significant increase in glucose, insulin and insulin resistance index and decrease in $\beta$-cell function. When given in combination ritonavir significantly $(P<0.05)$ altered the pharmacodynamics of gliclazide in both rats (normal and diabetic) and rabbits following both single and multiple dose treatments of ritonavir, which is reflected by a significant decrease in glucose, with increases in insulin, insulin resistance and $\beta$-cell function. The reduction in gliclazide effect was

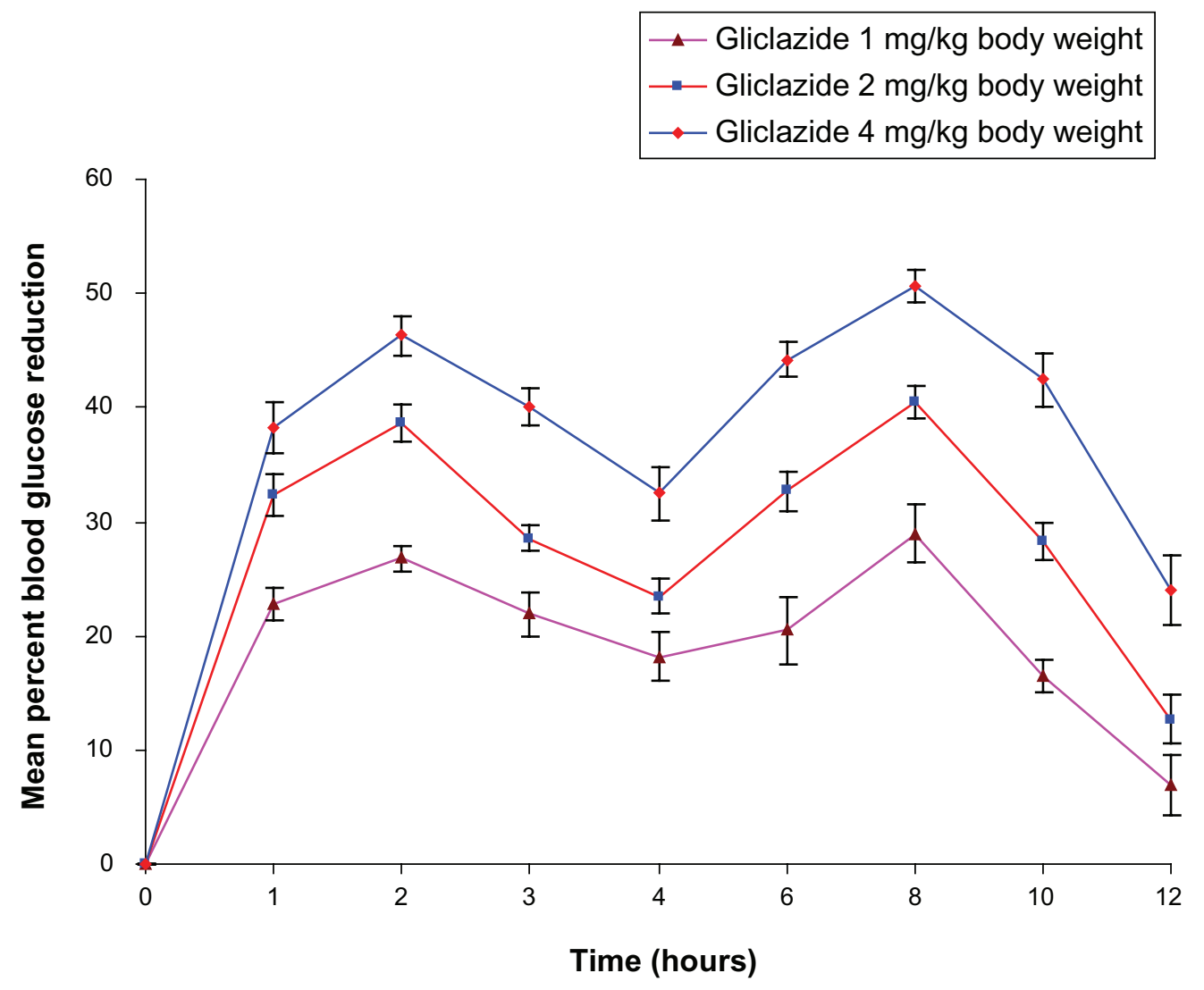

Figure I Dose effect relationship of gliclazide in normal rats $(\mathrm{N}=6)$. 

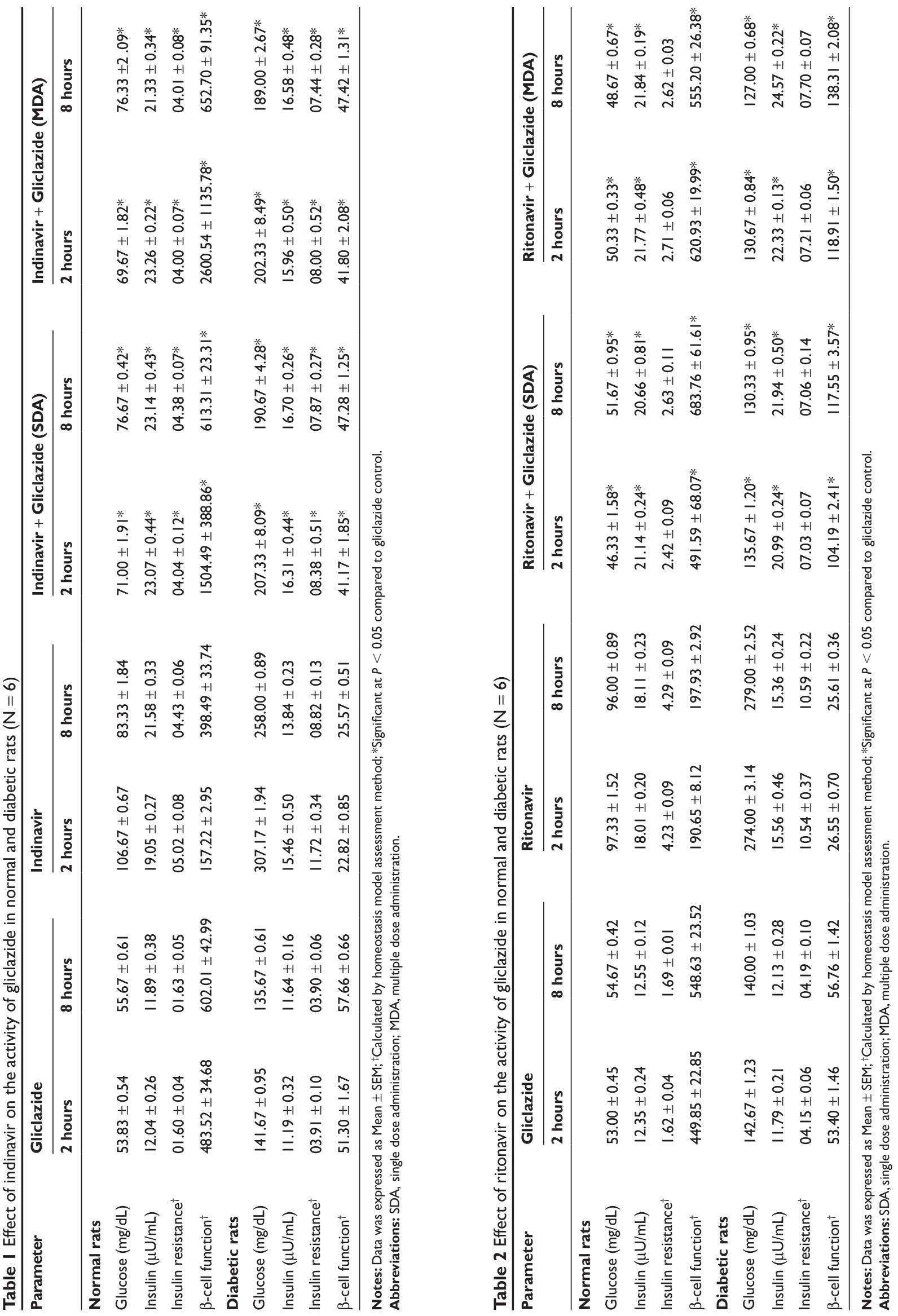
greater with the multiple dose treatment of ritonavir than the single dose treatment.

\section{Effect of atazanavir on the activity of gliclazide}

The levels of blood glucose, insulin, insulin resistance and $\beta$-cell function following gliclazide, atazanavir and their combination (single dose and multiple doses) are represented in Table 3 and Table 7. Atazanavir alone had no significant effect in glucose, insulin, insulin resistance index and $\beta$-cell function. When given in combination, atazanavir significantly $(P<0.05)$ altered the pharmacodynamics of gliclazide in both rats (normal and diabetic) and rabbits following both single and multiple dose treatments of atazanavir. This is reflected by a significant decrease in glucose, and an increase in insulin and $\beta$-cell function. The reduction in gliclazide effect is greater with the multiple dose treatment of atazanavir than the single dose treatment.

\section{Effect of efavirenz on the activity of gliclazide}

The levels of blood glucose, insulin, insulin resistance and $\beta$-cell function following gliclazide, efavirenz and their combination (single dose and multiple doses) are represented in Table 4 and Table 7. Efavirenz alone had no significant effect on glucose levels, insulin, insulin resistance index and $\beta$-cell function. When given in combination, efavirenz significantly $(P<0.05)$ altered the pharmacodynamics of gliclazide in both rats (normal and diabetic) and rabbits following both the single and multiple dose treatments of efavirenz, this is reflected by a significant increase in glucose and decrease in insulin levels. The $\beta$-cell function of gliclazide was significantly decreased in diabetic rats with this combination. The reduction in gliclazide effect is greater with the single dose treatment of efavirenz than the multiple dose treatments.

\section{Effect of nevirapine on the activity of gliclazide}

The levels of blood glucose, insulin, insulin resistance and $\beta$-cell function following gliclazide, nevirapine and their combination (single dose and multiple doses) are represented in Tables 5 and 8. Nevirapine alone had no significant effect in glucose, insulin, insulin resistance index and $\beta$-cell function. When given in combination nevirapine had no significant effect on the pharmacodynamics of gliclazide in both rats and rabbits following a single and multiple dose treatments

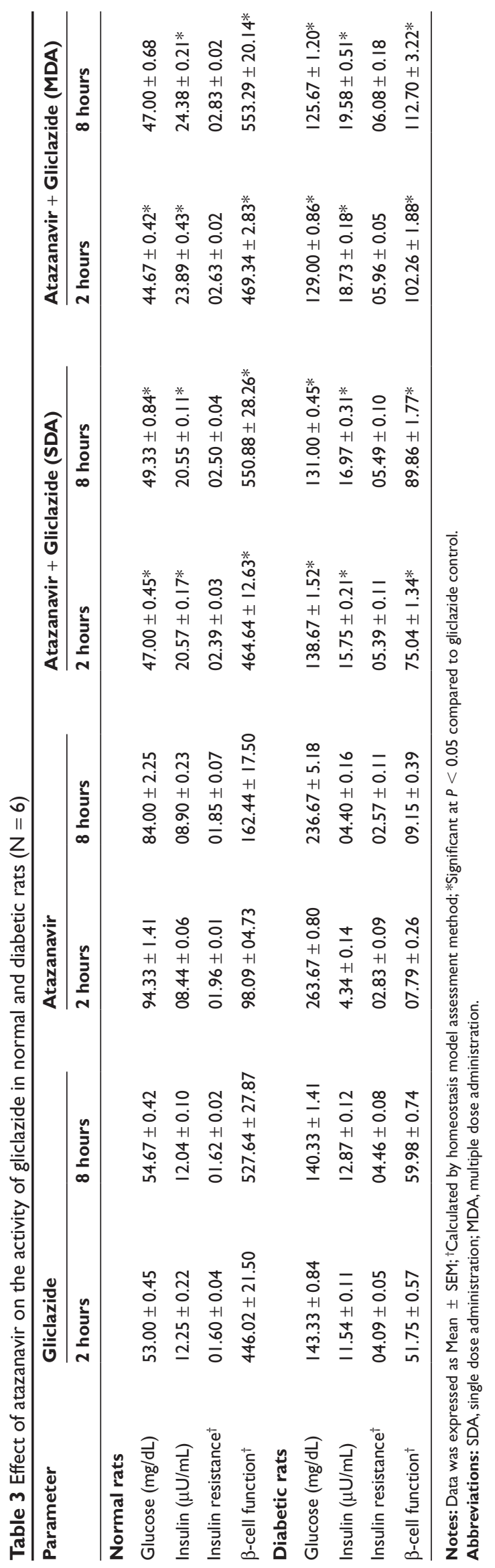




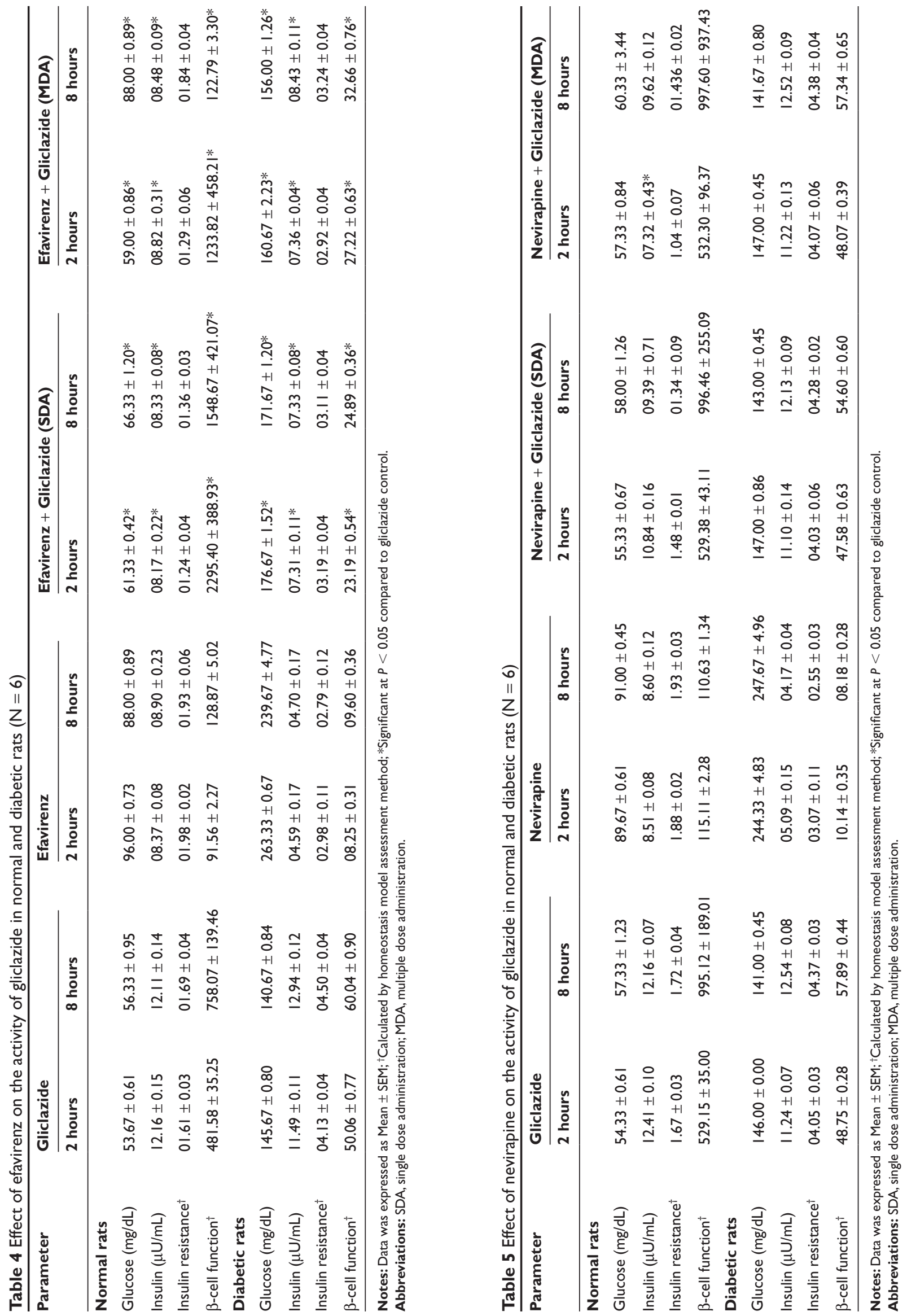


of nevirapine, with respect to glucose, insulin and insulin resistance index.

\section{Discussion}

HIV infected patients are likely to suffer with diabetes mellitus ${ }^{4}$ and hence most often antiretroviral drugs are co-administered along with oral antidiabetic drugs. HIV infection and diabetes are both chronic diseases that significantly affect lifestyle. When they intersect, the treatment regimens required for both diseases can be overwhelming for patients. Several studies have reported a prevalence of diabetes of $2 \%$ to $7 \%$ among HIV-infected patients receiving protease inhibitors ${ }^{26,27}$ and an additional $16 \%$ having impaired glucose tolerance. ${ }^{26}$ The incidence of diabetes mellitus in $\mathrm{HIV}$-infected patients has been estimated to range from $1 \%$ to $10 \%$ in various studies. ${ }^{27}$ In our study we have investigated the effect of widely used antiretroviral drugs from both PIs and NNRTIs on the activity of the widely used antidiabetic drug, gliclazide, as PIs are reported to have higher tendency to promote disorders of glucose-insulin homeostasis while NNRTIs are known to have a safer profile with respect to metabolic complications in HIV-infected patients. ${ }^{28-30}$

Previously we have reported ${ }^{12-15}$ the effect of these antiretroviral drugs on the activity of gliclazide with respect to blood glucose levels in animal models. However, in our present study we investigated the effect of antiretroviral drugs on the activity of gliclazide with respect to glucose, insulin, insulin resistance and $\beta$-cell function using HOMA, which is believed to be a more reliable and validated surrogate measure. ${ }^{25}$ In this study, the multiple dose effect of antiretroviral drugs on gliclazide activity was studied to determine the influence of the long term treatment with antiretroviral drugs since both are used for chronic conditions.
Drug interactions are often seen in clinical practice and the mechanisms of such interactions are often evaluated in animal models both rodent and nonrodent. We studied the influence of antiretroviral drugs on the pharmacodynamics of gliclazide in rats (rodents) and rabbits (nonrodent). The normal rat model served to quickly identify the hypothesized interaction and the diabetic rat model served to validate the response in conditions that mirror the clinical application of these drugs. The rabbit model, another quite dissimilar species also validated the occurrence of such an interaction. Usually, if the interaction is observed in both rodent and non-rodent species, it is likely to occur in humans. Although animal models can never replace the need for comprehensive human trials, the use of animal models can provide important insights in understanding and evaluation of potent drug interactions. Since such a small amount of blood was required for this study, the blood samples were collected by retro-orbital puncture and marginal ear vein as they were reported to be suitable methods when small samples of blood were required. Diabetes was induced with alloxan monohydrate, since it was more economical and easily available.

Rats are known to be more sensitive to gliclazide response. So we conducted a dose effect relationship study of gliclazide to select the oral dose which produces approximately $35 \%$ of blood glucose reduction in rats. Consistent with our previous studies $^{12-15}$ and literature, ${ }^{1,31}$ gliclazide produced a biphasic response (at 2 hours and 8 hours) in the rat model when administered alone, which may be due its biliary excretion and entero hepatic cycling. Gliclazide is known to produce hypoglycemic (antihyperglycemic) activity by pancreatic (stimulating insulin secretion by blocking $\mathrm{K}^{+}$channels in the pancreatic $\beta$ cells) $)^{32,33}$ and extra pancreatic (increasing the tissue uptake of glucose $)^{34,35}$ mechanisms. Such an effect was

Table 6 Effect of indinavir and ritonavir on the activity of gliclazide in normal rabbits $(\mathrm{N}=6)$

\begin{tabular}{|c|c|c|c|c|}
\hline Parameter & Glucose (mg/dL) & Insulin $(\mu \mathrm{U} / \mathrm{mL})$ & Insulin resistance ${ }^{\dagger}$ & $\beta$-cell function ${ }^{\dagger}$ \\
\hline \multicolumn{5}{|l|}{ Indinavir vs gliclzide } \\
\hline Gliclazide & $59.33 \pm 0.84$ & $06.90 \pm 0.47$ & $\mathrm{I} .0 \mathrm{I} \pm 0.07$ & $1190.88 \pm 415.26$ \\
\hline Indinavir & $110.67 \pm 0.99$ & $17.55 \pm 0.29$ & $4.80 \pm 0.09$ & $132.85 \pm 3.25$ \\
\hline Indinavir + gliclazide (SDA) & $72.33 \pm 1.82 *$ & $22.97 \pm 0.44^{*}$ & $4.11 \pm 0.14 *$ & $1201.76 \pm 313.82 *$ \\
\hline Indinavir + gliclazide (MDA) & $70.00 \pm \mid .7 I^{*}$ & $23.15 \pm 0.30 *$ & $04.00 \pm 0.06 *$ & $2395.80 \pm 1129.14^{*}$ \\
\hline \multicolumn{5}{|l|}{ Ritonavir vs gliclzide } \\
\hline Gliclazide & $53.33 \pm 0.42$ & $11.87 \pm 0.26$ & $01.56 \pm 0.33$ & $444.87 \pm 13.16$ \\
\hline Ritonavir & $104.00 \pm 0.52$ & $17.19 \pm 0.10$ & $04.4 I \pm 0.04$ & $|5| .00 \pm|.5|$ \\
\hline Ritonavir + gliclazide (SDA) & $59.00 \pm 0.45^{*}$ & $21.40 \pm 0.22 *$ & $03.12 \pm 0.05$ & $2059.28 \pm 219.07^{*}$ \\
\hline Ritonavir + gliclazide (MDA) & $56.00 \pm 0.52 *$ & $22.30 \pm 0.27^{*}$ & $03.09 \pm 0.06$ & $\mid 184.14 \pm 93.83 *$ \\
\hline
\end{tabular}

Notes: Data was expressed as Mean \pm SEM; ${ }^{\dagger}$ Calculated by homeostasis model assessment method; *Significant at $P<0.05$ compared to gliclazide control. Abbreviations: SDA, single dose administration; MDA, multiple dose administration. 
Table 7 Effect of atazanavir and efavirenz on the activity of gliclazide in normal rabbits $(\mathrm{N}=6)$

\begin{tabular}{|c|c|c|c|c|}
\hline Parameter & Glucose (mg/dL) & Insulin $(\mu \mathrm{U} / \mathrm{mL})$ & Insulin resistance ${ }^{\dagger}$ & $\beta$-cell function ${ }^{\dagger}$ \\
\hline \multicolumn{5}{|l|}{ Atazanavir vs gliclzide } \\
\hline Gliclazide & $60.00 \pm 0.73$ & $11.89 \pm 0.06$ & $1.76 \pm 0.02$ & $585.04 \pm 608.53$ \\
\hline Atazanavir & $98.67 \pm 1.61$ & $08.03 \pm 0.11$ & $1.96 \pm 0.05$ & $81.71 \pm 2.75$ \\
\hline Atazanavir + gliclazide (SDA) & $53.33 \pm 0.42 *$ & $19.44 \pm 0.28^{*}$ & $2.56 \pm 0.04$ & $730.36 \pm 29.04 *$ \\
\hline Atazanavir + gliclazide (MDA) & $51.00 \pm 0.68^{*}$ & $22.10 \pm 0.21 *$ & $2.78 \pm 0.02$ & $674.14 \pm 36.20^{*}$ \\
\hline \multicolumn{5}{|l|}{ Efavirenz vs gliclzide } \\
\hline Gliclazide & $60.67 \pm 0.67$ & $\mathrm{II} .83 \pm 0.20$ & $1.77 \pm 0.04$ & $2747.44 \pm 625.78$ \\
\hline Efavirenz & $96.33 \pm 0.61$ & $08.21 \pm 0.13$ & $1.95 \pm 0.02$ & $88.89 \pm 2.77$ \\
\hline Efavirenz + gliclazide (SDA) & $70.00 \pm 0.52 *$ & $07.86 \pm 0.30 *$ & $1.38 \pm 0.05$ & $414.09 \pm 27.09 *$ \\
\hline Efavirenz + gliclazide (MDA) & $67.00 \pm 0.45^{*}$ & $07.73 \pm 0.13^{*}$ & $1.28 \pm 0.01$ & $749.04 \pm 87.16^{*}$ \\
\hline
\end{tabular}

Notes: Data was expressed as Mean \pm SEM; ${ }^{\dagger}$ Calculated by homeostasis model assessment method; $*$ Significant at $P<0.05$ compared to gliclazide control. Abbreviations: SDA, single dose administration; MDA, multiple dose administration.

not observed in our previous studies in rabbits (maximum response at 3 hours), which is consistent with the available literature. Based on this background we selected 2 hours and 8 hours for the rat experiments and 3 hours for the rabbit experiments as blood sampling time points to measure the glucose-insulin homeostasis.

The elevated insulin levels together with increased glucose levels suggests an insulin resistant state. ${ }^{10,11}$ Diabetes related glucose intolerance is characterized by an increase in insulin resistance and alterations in insulin clearance, insulin sensitivity of hepatic and peripheral tissues. In this study indinavir and ritonavir produced a significant impact on glucoseinsulin homeostasis concomitant with insulin resistance and impaired in $\beta$-cell function in both rats and rabbits. These effects were augmented in the diabetic animals in comparison to the normal controls indicating the potency of these drugs towards exacerbation of existing diabetes mellitus. Comparatively indinavir showed a potent impact on glucose-insulin homeostasis in our study. Atazanavir, efavirenz and nevirapine alone did not have any significant effect on glucose-insulin homeostasis that indicates that glucose-insulin homeostasis disorders associated with antiretroviral drugs are drug specific, but not a class-specific. All these observations are consistent with our previous studies. ${ }^{12-15}$

In combination, the pharmacodynamics of gliclazide was significantly reduced in the presence of indinavir following both single and multiple dose treatments in the rat (normal and diabetic) and rabbit models and it confirmed the presence of a potential interaction between gliclazide and indinavir. The possible mechanism of this pharmacodynamic interaction appears to be due to the opposing effects of gliclazide and indinavir on insulin resistance, insulin release or tissue uptake of glucose as reflected in our study.

In contrast to the theoretical expectation and consistent with our previous study, ${ }^{13}$ the pharmacodynamics of gliclazide was enhanced by ritonavir following single and multiple dose administration in rats and rabbits, even though ritonavir alone has shown significant alterations in glucose-insulin homeostasis. Gliclazide is known to be metabolized by the hepatic microsomal enzymes CYP2C9 primarily and partly by CYP3A4. ${ }^{9,31}$ Ritonavir is a well known potent inhibitor of CYP $3 \mathrm{~A} 4{ }^{36}$ and used to enhance the pharmacokinetic and anti-HIV activity profiles of the concomitantly administered PIs. ${ }^{37}$ Since ritonavir increased blood glucose and insulin

Table 8 Effect of nevirapine on the activity of gliclazide in normal rabbits $(\mathrm{N}=6)$

\begin{tabular}{lllll}
\hline Parameter & Glucose $(\mathbf{m g} / \mathbf{d L})$ & Insulin $(\mu \mathbf{U} / \mathbf{m L})$ & Insulin resistance $^{\dagger}$ & $\beta$-cell function \\
\hline Nevirapine vs gliclzide & & & & $2023.527 \pm 562.45$ \\
Gliclazide & $60.00 \pm 0.73$ & $11.03 \pm 0.12$ & $1.63 \pm 0.03$ & $136.90 \pm 8.30$ \\
Nevirapine & $86.33 \pm 1.31$ & $8.76 \pm 0.37$ & $1.87 \pm 0.09$ & $1028.46 \pm 136.28^{\dagger}$ \\
Nevirapine + gliclazide (SDA) & $58.67 \pm 0.67$ & $11.03 \pm 0.18$ & $1.60 \pm 0.04$ & $2675.20 \pm 536.40 *$ \\
Nevirapine + gliclazide (MDA) & $61.00 \pm 0.45$ & $11.22 \pm 0.17$ & $1.69 \pm 0.02$ & \\
\hline
\end{tabular}

Notes: Data was expressed as Mean \pm SEM; ${ }^{\dagger}$ Calculated by homeostasis model assessment method; ${ }^{*}$ Significant at $P<0.05$ compared to gliclazide control. Abbreviations: SDA, single dose administration; MDA, multiple dose administration. 
levels on its own, the increase in the effect of gliclazide on blood glucose might be due to improved blood gliclazide level in the presence of ritonavir as there is a possibility of a pharmacokinetic interaction at a metabolic level rather than a pharmacodynamic interaction. However, it would need to be confirmed by conducting further pharmacokinetic studies in animal models.

In combination, atazanavir has enhanced the pharmacodynamics of glicalzide with respect to glucose-insulin homeostasis and consistent with our previous study it confirms the pharmacokinetic interaction, at a metabolic level, as per our previous study, as atazanavir inhibited CYP3A4 and CYP2C9-mediated drug metabolism that leads to raised serum levels of gliclazide. ${ }^{14}$

This study revealed additional information regarding the safety profile of efavirenz and nevirapine in both the normal and diabetic condition. However, contrary to the theorized expectation, the activity of gliclazide was significantly reduced in the presence of efavirenz in rats (normal and diabetic) and rabbits with respect to glucose-insulin homeostasis. Additionally it confirms the presence of a potential interaction between efavirenz and gliclazide. The possible mechanism of such an interaction between efavirenz and gliclazide may be due to the increased metabolism of hepatic microsomal enzymes by efavirenz, as it is known to be a potent CYP3A4 inducer. ${ }^{15,38,39}$ However this would need to be confirmed by further pharmacokinetic interaction studies.

With respect to the safety profile of nevirapine with gliclazide and glucose-insulin homeostasis the results of this study are consistent with the findings of our previous study. ${ }^{15}$ However, the metabolic complications arising from $\mathrm{HIV}$-infection and/or antiretroviral therapy are multifactorial and complex therefore the study of other possible factors and mechanism(s) behind these interactions can't be ruled out.

\section{Conclusion}

This study has confirmed that glucose-insulin homeostasis disorders associated with antiretroviral drugs are not a class specific, but are drug specific. Since the interaction between antiretroviral drugs (indinavir, ritonavir, atazanavir and efavirenz) and gliclazide was seen in two dissimilar species, it is likely to occur in humans, leading to increased/decreased activity of gliclazide, which may need dosage adjustment. Hence care should be taken when the combinations of these two drug types prescribed for the treatment of diabetic patients. Since there is no interaction between nevirapine and gliclazide in any species, this will probably be a safe combination of drugs in humans too. However the present study indicates the need for further studies to determine the relevance of these interactions in human beings and to understand the exact pharmacodynamic mechanisms of such interactions.

\section{Disclosures}

SK Mastan participated in the design, carried out the study and drafted the manuscript. K Eswar Kumar conceived of the study, participated in the design of the study and performed the statistical analysis and interpretation of the data. The authors report no conflicts of interest in this work.

\section{Acknowledgements}

The authors are thankful to Aurobindo Pharma Ltd, Hyderabad and Micro Labs, Bangalore for supplying gift samples of the antiretroviral drugs and gliclazide, respectively. The authors are grateful to Dr Katherine Samaras, Head, Diabetes and Obesity Clinical Group, Garvan Institute of Medical Research, New South Wales 2010, Australia for her kind help and support during the literature survey.

\section{References}

1. Satyanarayana S, Kilari EK. Influence of nicorandil on the pharmacodynamics and pharmacokinetics of gliclazide in rats and rabbits. Mol Cell Biochem. 2006;291:101-105.

2. Saely CH, Aczel S, Marte T. Cardiovascular complications in type 2 diabetes mellitus depends on the coronary angiographic state rather than on the diabetes state. Diabetologia. 2004;47:145-146.

3. Wild SG, Roglic A, Green R, King H. Global prevalence of diabetes. Estimated for the year 2000 and projection for 2030. J Diabetes Care. 2004;27:1047-1054.

4. Hruz PW. Molecular mechanisms for altered glucose homeostasis in HIV infection. Am J Infect Dis. 2006;2:187-192.

5. Leow MK, Addy CL, Mantzoros CS. Human immunodeficiency virus/ highly active antiretroviral therapy-associated metabolic syndrome: clinical presentation, pathophysiology, and therapeutic strategies. J Clin Endocrinol Metab. 2003;88:1961-1976.

6. Dube MP. Disorders of glucose metabolism in patients infected with human immunodeficiency virus. Clin Infect Dis. 2000;31:1467-1475.

7. Zimmet P, Alberti KGMM, Shaw J. Global and societal implications of the diabetes epidemic. Nature. 2001;141:782-787.

8. Martinez E, Arnaiz JA, Podzamczer D, et al. Substitution of nevirapine, efavirenz, or abacavir for protease inhibitors in patients with human immunodeficiency virus infection. N Engl J Med. 2003;349:1036-1046.

9. Mastan SK, Chaitanya G, Reddy KR, Kumar KE. An appraisal to the special sulphonylurea: gliclazide. Pharmacologyonline. 2009;1:254-269.

10. Cefalu WT. Insulin resistance: cellular and clinical concepts. Exp Biol Med. 2001;226:13-26.

11. Reaven G. The metabolic syndrome or the insulin resistance syndrome? Different names, different concepts, and different goals. Endocrinol Metab Clin North Am. 2004;33:283-303.

12. Mastan SK, Eswar Kumar K. Influence of indinavir on the pharmacodynamic activity of gliclazide in rats and rabbits. Int J Integr Biol. 2009;7:16-21.

13. Mastan SK, Eswar Kumar K. Effect of ritonavir on the pharmacodynamics of gliclazide in animal models. Diabetologia Croatica. 2009; 38:105-113.

14. Mastan SK, Eswar Kumar K. Influence of atazanavir on the pharmacodynamics and pharmacokinetics of gliclazide in animal models. Int $J$ Diabetes Mellitus. 2009; In press DOI 10.1016/j.ijdm.2009.10.001. 
15. Mastan SK, Eswar Kumar K. Influence of non-nucleoside reverse transcriptase inhibitors (efavirenz and nevirapine) on the pharmacodynamic activity of gliclazide in animal models. Diabetology and Metabolic Syndrome. 2009;1:15.

16. Lawrence DR, Bacharach AL, editors. Evaluation of drug activities: Pharmacometrics. Vol 1. New York, NY: Academic Press; 1964.

17. Yamaji H, Matsumura Y, Yashikawa Y, Takada K. Pharmacokinetic interactions between HIV-protease inhibitors in rats. Biopharm Drug Dispos 1999;20:241-247.

18. Shibata N, Gao W, Okamoto H, et al. Drug interactions between HIV protease inhibitors based on physiologically-based pharmacokinetic model. J Pharmaceutical Sciences. 2002;91:680-689.

19. Berruet N, Sentenac S, Auchere D, Gimenez F, Farinotti R, Fernandez C. Effect of efavirenz on intestinal p-glycoprotein and hepatic function in rats. J Pharm Pharm Sci. 2005;8:226-234.

20. Kishimoto W, Takano J, Senda C, et al. Quantitative prediction of in vivo drug interactions between nevirapine and antifungal agents from in vitro data in rats. Biol Pharm Bull. 2000;23:1027-1032.

21. Heikkila RE. The prevention of alloxan-induced diabetes in mice by dimethyl sulfoxide. Eur J Pharmacol. 1977;44:191-193.

22. Riley V. Adaptation of orbital bleeding technique to rapid serial blood studies. Proc Soc Exp Biol Med. 1960;104:751-754.

23. Trinder P. Determination of blood glucose using an oxidase-peroxidase system with a non carcinogenic chemogen. J Clin Pathol. 1969;22: $158-161$

24. Matthews DR, Hosker JP, Rudenski AS, et al. Homeostasis model assessment: insulin resistance and $\beta$-cell function from fasting plasma glucose and insulin concentrations in man. Diabetologia. 1985;28. 412-419.

25. Bonora E, Targher G, Alberiche M, et al. Homeostasis model assessment closely mirrors the glucose clamp technique in the assessment of insulin sensitivity: studies in subjects with various degrees of glucose tolerance and insulin sensitivity. Diabetes Care. 2000;23:57-63.

26. Carr A, Samaras K, Thorisdottir A, et al. Diagnosis, prediction, and natural course of HIV-1 protease-inhibitor-associated lipodystrophy, hyperlipidaemia, and diabetes mellitus: a cohort study. Lancet. 1999;353: 2093-2099.

27. Samaras K. Prevalence and pathogenesis of diabetes mellitus in HIV-1 infection treated with combined antiretroviral therapy. JAcquir Immune Defic Syndr. 2009;50:499-505.
28. Saag MS, Powderly WG, Schambelan M, et al. Switching antiretroviral drugs for treatment of metabolic complications in HIV-1 infection: Summary of selected trials. Topics in HIV Med. 2002;10:47-51.

29. Martínez E, García-Viejo MA, Blanco JL, et al. Impact of switching from human immunodeficiency virus type 1 protease inhibitors to efavirenz in successfully treated adults with lipodystrophy. Clin Infect Dis. 2000;12:1266-1273.

30. Martínez E, Conget I, Lozano L, Casamitjana R, Gatell JM. Reversion of metabolic abnormalities after switching from HIV-1 protease inhibitors to nevirapine. AIDS. 1999;13:805-810.

31. Satyanarayana S, Eswar Kumar K, Rajasekhar J, Thomas L, Rajanna S, Rajanna B. Influence of aqueous extract of fenugreek-seed powder on the pharmacodynamics and pharmacokinetics of gliclazide in rats and rabbits. Therapy. 2007;4:457-463.

32. Campbell DB, Lavielle R, Nathan C. The mode of action on clinical pharmacology of gliclazide a review. Diabetes Res Clin Pract. 1991;14: S21-S36.

33. Chiasson JL, Hamet P, Vercly M. The effect of Diamicron (R) on the secretion and action of insulin. Diabetes Res Clin Pract. 1991;14: S47-S51.

34. Vanhaeften TW, Vaneman TF, Gerich JE. Influence of gliclazide on glucose stimulated insulin release in man. Metabolism. 1991;40:751-755.

35. Wajchenberg BL, Santomano ATMG, Porrelli RN. Effect of sulfonylurea (gliclazide) treatment on insulin sensitivity and glucose mediated, glucose disposal in patients with non-insulin dependent diabetes mellitus (NIDDM). Diabetes Res Clin Pract. 1993;20:147-154.

36. Kumar GN, Rodrigues AD, Buko AM, Denissen JF. Cytochrome P450-mediated metabolism of the HIV-1 protease inhibitor ritonavir (ABT-538) in human liver microsomes. J Pharmacol Exp Ther. 1996; 277:423-431.

37. Acosta EP. Pharmacokinetic enhancement of protease inhibitors. J Acquir Immune Defic Syndr. 2002;29:S11-S18.

38. Mouly S, Lown KS, Kornhausir D, et al. Hepatic but not intestinal CYP3A4 displays dose-dependent induction by efavirenz in humans Clin Pharmacol Ther. 2002;72:1-9.

39. Hariprasad N, Nallani SC, Sane RS, Buckley DJ, Buckley AR, Desai PB Induction of CYP3A4 by efavirenz in primary human hepatocytes: comparison with rifampin and phenobarbital. J Clin Pharmacol. 2004 44:1273-1281.
Journal of Experimental Pharmacology

\section{Publish your work in this journal}

The Journal of Experimental Pharmacology is an international, peerreviewed, open access journal publishing original research, reports, reviews and commentaries on all areas of laboratory and experimental pharmacology. The manuscript management system is completely online and includes a very quick and fair peer-review system.

\section{Dovepress}

Visit http://www.dovepress.com/testimonials.php to read real quotes from published authors. 